\title{
Coral immunology and resistance to disease
}

\author{
K. C. Reed $^{1, *}$, E. M. Muller ${ }^{2}$, R. van Woesik ${ }^{2}$ \\ ${ }^{1} 1651$ Country Walk Drive, Orange Park, Florida 32003, USA \\ ${ }^{2}$ Department of Biological Sciences, Florida Institute of Technology, 150 West University Boulevard, \\ Melbourne, Florida 32901, USA
}

\begin{abstract}
Scleractinian corals (phylum Cnidaria, class Anthozoa) have innate immunological responses against infections. Research has recently suggested that corals also possess an adaptivelike immunological repertoire that recognizes specific pathogens and allografts. While evolutionarily distinct, the corals' innate and adaptive-like immunity systems are not mutually exclusive because the phagocytic cells of the non-specific, innate immune system may activate specific adaptive immunological responses. Warming oceans may immunocompromise coral hosts, making them more susceptible to tropical marine diseases, independent of the virulence of the pathogen. The ability of corals to ward off both primary and opportunistic infections, through adaptive-like mechanisms, may play a critical role in the corals' ability to fight future disease infection. Here we show evidence that corals possess immunological repertoires that extend well beyond simple innate defenses. The extent to which corals have developed such an adaptive-like immune repertoire will determine whether corals will survive climate change and other anthropogenic disturbances.
\end{abstract}

KEY WORDS: Coral · Anthozoan genome · Coral immunology · Holobiont · Coral amoebocytes · Symbionts · Compromised-host hypothesis · Acropora millepora

\section{INTRODUCTION}

There are 2 types of animal immunological responses: innate and adaptive. The innate-immunological response is an integrated response that is characterized by mechanisms that defend the host from infection by other organisms. Innate-immune defenses are (1) an immediate defense mechanism, (2) genetically determined, and (3) known to appear early in metazoan evolution. The innate response is a generalized response that may remove or retard simultaneous infection by several species of pathogens. The adaptive-immunological response system, however, involves an ability to recognize and respond to specific pathogens; reinfection generally results in a reduction in susceptibility. Most organisms have some type of an innate immunological defense strategy, whereas only some vertebrates, but all mammals, possess a fully adaptive ability to respond to infection.

Modern immunological texts attribute 4 characteristics to vertebrate adaptive immunity: (1) antigenic specificity, which confers immunological memory; (2) genetic diversity allowing the immune system to recognize billions of unique structures on antigens; (3) self/non-self recognition to prevent fatal reactions; and (4) immunologic memory, which creates a heightened state of immune reactivity upon reencounter with the same antigen. Yet, the adaptive and innate immunity systems are not mutually exclusive. The phagocytic cells of the nonspecific (innate) immune response activate specific adaptive immune responses. Still, all 4 criteria are necessary if the animal's immune system is strictly adaptive. Therefore, we use the term 'adaptive-like' to describe immunological responses that appear different from the innate system but do not necessarily show all 4 criteria of the mammalian adaptive immune system.

Experimental evidence suggests that indeed some invertebrates, such as scleractinian corals, show adaptive-like immunological responses (Hildemann et al. 1977, Rosenberg et al. 2007), possibly shifting the historical paradigm away from the concept that inverte- 
brates contain only innate-immune defenses. The Hildemann group found that isografts (using the same colony) of the Hawaiian stony coral Montipora verrucosa were consistently compatible and fused within days of grafting, whereas allografts (from different colonies) resulted in soft-tissue death. Furthermore, the reaction time was accelerated by almost $50 \%$ when the same allograft pairs were reset. The authors summarized their results as showing 'both specificity in transplantation alloimmunity and extensive antigenic polymorphism among genetically separate $M$. verrucosa.' (Hildemann et al. 1977). Moreover, researchers discovered that Vibrio shiloi, the bacteria that previously infected the stony coral Oculina patagonica in the eastern Mediterranean, is now lysed upon entering the coral tissue (Rosenberg et al. 2007). How is such an expanded immunological repertoire possible for scleractinian corals?

Metazoan invertebrates have evolved polymorphic histocompatibility mechanisms without the use of antibodies. For example, the innate-immune response of a freshwater hydrozoan polyp was found to be mediated by unconventional toll-like receptor (TLR) signaling (Bosch et al. 2009). Additionally, genetic studies of a marine hydrozoan, Hydractinia symbiolongicarpus, revealed an invertebrate histocompatibility complex. Tools are now at hand to isolate homologs of higher chordate immune system molecules and identify invertebrate allorecognition determinants (Mokady \& Buss 1996, Cadavid et al. 2004, Dishaw \& Litman 2009). This type of genetic approach has not yet been fully applied to reef corals.

Conventional wisdom suggests that scleractinian corals possess only nonspecific innate defense mechanisms against infection and disease. It is further supposed that corals lack the memory and specificity of an adaptive-immune system. While corals and anemones use mucus production as a primary defense and possess a functional cellular immune system analogous to vertebrate immune systems, no humoral immunity has been identified in corals (Stoskopf 2006). Recent research and some historical studies suggest that corals may possess defense processes beyond the innate system of immunology (Hildemann et al. 1977, Rosenberg et al. 2007). In fact, using expressed sequence tags (ESTs), the anthozoan Acropora millepora has a genome that more closely matches the human sequence than does that of a fruit fly or a hermaphroditic nematode (Kortschak et al. 2003). A recent study examining 26845 ESTs of the coral A. millepora and the sea anemone Nematostella vectensis showed that the full diversity of metazoan signaling pathways are represented in the basal class of Anthozoa (Technau et al. 2005).

\section{INNATE-IMMUNOLOGICAL RESPONSES}

Recent findings also suggest that many, but not all, Cnidaria contain TLRs (Miller et al. 2007). TLRs recognize microbial molecules, activate the immune cell responses, and signal cells to secrete immunostimulatory cytokines, lysozyme complement, and interferon (an antiviral for uninfected cells). A freshwater Hydra showed unconventional TLR signaling mediated by the epithelium (Bosch el al. 2009). The genome sequences of the starlet sea anemone Nematostella vectensis, the scleractinian coral Acropora millepora and a solitary freshwater polyp Hydra magnipapillata have shown several differences among the key components of the innate-immune repertoire (Miller et al. 2007). While the Anthozoa class of cnidarian animals ( $N$. vectensis and A. millepora) possessed a canonical TLR pathway, H. magnipapillata did not. This new genomic information implies that Hydra may have undergone substantial secondary gene loss during evolution from the basal cnidarian class Anthozoa, and that corals possess a more advanced innate-immunological response. The detection of complement-C3 and several membrane-attack-complex/perforin-domain proteins suggests that a prototypic complement effect or pathway may exist in anthozoans, but not in hydrozoans (Miller et al. 2007). Complement is a complex mixture of proteins which, when triggered through different pathways, causes cascades of zymogens that may result in inflammation or opsonization to enhance phagocytosis.

\section{Anatomical barriers}

A primary form of the generalized innate response in scleractinian coral colonies involves the shedding of large sheets of mucus, which cleanses colonies of sediments and potential pathogens (Fig. 1). Mucus production is a byproduct of the symbionts (Symbiodinium) found within the tissue of the coral-host. The photosynthates released by the symbionts are utilized by the host, which in turn produce organic wastes that benefit the symbionts; the relationship is therefore mutualistic. Translocation of glycerol and other byproducts to the coral host range from 78 to $97 \%$ of total net carbon fixed (Davies 1984, Muscatine et al. 1984). This carbon is used to synthesize new animal biomass, but is also released as mucus.

Coral mucus is central to the host's defense mechanisms against infectious disease (Brown \& Bythell 2005). For example, Ritchie (2006) tested Acropora palmata mucus for inhibition of human bacteria found in Florida Keys canal water, African dust microbes, and water column marine bacteria. Serial dilutions of the 


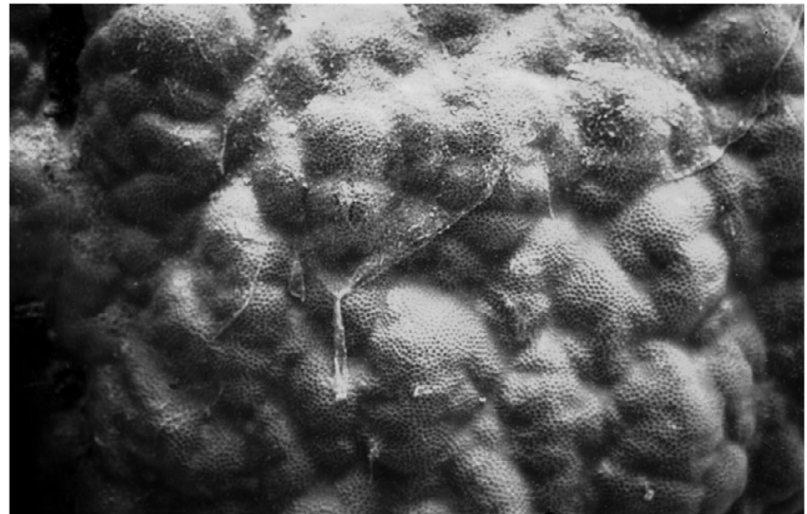

Fig. 1. Porites australiensis. Production of mucus sheets, in this case to trap sediments and suspended particulate matter, which are periodically sloughed off the host coral

mucus from unbleached elkhorn coral colonies demonstrated greater antibacterial activity to tester stains of Bacillus subtilis, Staphylococcus aureus, Salmonella typhimurium and Serratia marcescens than mucus from bleached colonies. Also, A. palmata mucus collected in April 2005, before bleaching, inhibited human bacterial growth from Florida Keys canal water approximately 2.5 times more than it inhibited bacteria growth of microbes in African dust and water column bacteria. Notably, mucus collected from the same colonies during anomalously high water temperatures, when corals were pale and stressed, showed no inhibitory effect against the same microbes (Ritchie 2006). Therefore, while the presence of endosymbionts in a coral host is integral for mucus production, symbionts also appear to influence the coral's antimicrobial properties. Yet, the defensive properties of mucus may be simply an exaptation, not an adaptation (Gould \& Vrba 1982). Discharging large amounts of mucus certainly protects the coral host from microbes, but mucus production per se may be simply a consequence of the symbiosis - an oversupply of glycerol to the host - not the result of a highly derived adaptive defense against infectious diseases (i.e. an exaptation).

\section{Immune proteins, antibiotic, and antifungal properties}

Immune proteins, antioxidants, and antimicrobial activity have been recorded in the sea fan Gorgonia ventalina. Couch et al. (2008) showed that environmental conditions, more so than colony age, caused greater variation in the measured levels of immune proteins (enzymes), antioxidants, and antimicrobial activity in the sea fans. Components of the innate-immune defense system included lysozyme-like enzymes, peroxi- dase, prophenoloxidase, superoxide dismutase (an antioxidant) and exochitinase. In addition, colonies of Montastraea faveolata with yellow-band disease showewd high levels of lysozyme-like enzymes and antibacterial activity (Mydlarz et al. 2009). These responses were found in both apparently healthy and diseased samples within the same colony, suggesting a systemic response to infection. Chemical defenses have also been found on scleractinian corals in the Pacific Ocean (Koh 1997). Few of the 100 different coral species analyzed from the Great Barrier Reef in Queensland, Australia showed antibacterial activity, but most displayed anti-cyanobacterial defenses. Those corals that did show antibacterial capabilities also had fewer bacteria present on their surfaces. Other studies have shown that Gorgonia ventalina were able to stop the progression of fungal infections, although not able to totally rid themselves of those infections (ToledoHernandez et al. 2007a,b, Zuluaga-Montero 2009).

\section{Prophenoloxidase system}

The prophenoloxidase system, and its melanotic end products, controls a major innate defense system in invertebrates, which allows melanization of pathogens and damaged tissues. This system requires feedback by either enzymatic control or overproduction of highly toxic and reactive compounds (Cerenius \& Soderhall 2004). Melanization can halt infection of invertebrates, but invertebrates need a recognition system to initiate the cascade to use or produce this effect. In arthropods, zymogens, or proenzymes (such as phenoloxidase and prophenoloxidase, PPO) are activated in a stepwise process when microbial cell wall constituents activate serine proteinases (Ratcliffe 1991, Cerenius \& Soderhall 2004).

Although the mechanism inducing melanization is unknown in cnidarians, melanin deposits are found around lesions of sea fans (Petes et al. 2003) and act as a defense against fungal pathogens. The prophenoloxidase pathway has also been documented in 2 scleractinian corals, Acropora millepora and a massive Porites sp. (Palmer et al. 2008). However, each species used the melanization pathway differently: A. millepora showed higher concentrations of PPO, while the Porites sp. had increased melanin production in areas of non-normal pigmentation. PPO was significantly elevated in colonies of Montastrea faveolata studied during a season of unusually elevated sea surface temperatures, although the reasons for the upregulation are not fully understood (Mydlarz et al. 2009). Interspecific differences in the melanization pathway provide some insight into species-specific responses to disease. 


\section{Phagocytic mechanisms and inflammatory response}

Under stress, corals also seem to increase symbiont phagocytosis (Titlyanov et al. 1996). Phagocytosis, the consumption of particles (including microbes) by wandering cells, was first documented in invertebrates in 1886 by Elie Metchnikoff (Metchnikoff 1886). Phagocytosis within anthozoan amoebocytes occurs as 2 types, hyaline and granular. Hyaline amoebocytes of the sea anemone Actinia equina phagocytize and kill the gram-negative bacterium Psychrobacter (formerly Moraxella immobilis), with approximately $40 \%$ of the hyaline amoebocytes ingesting one or more bacteria over 45 min (Hutton \& Smith 1996). Granular amoebocytes have been found adjacent to areas with fungal infections (Mydlarz et al. 2008).

The digestion of symbionts by their own coral hosts was first found in scleractinian corals by Boschma (1925). Boschma observed different stages of zooxanthellae digestion in the mesenterial filaments of Astrangia danae and concluded that zooxanthellae are a part of that coral's normal diet. Titlyanov et al. (1996) and, most recently, Downs et al. (2009) confirmed Boschma's findings. Digestion of symbionts increases when corals are stressed or, more likely, when the symbionts are dysfunctional and not producing photosynthates (i.e. glycerol: Titlyanov et al. 1996).

Amoebocytes also influence anthozoan lesion healing; different cells in the host demonstrate phagocytic activity depending on the type of trauma (Olano \& Bigger 2000). Amoebocytes migrate from uninjured areas to wound sites within the soft coral Plexaurella fusifera (Meszaros \& Bigger 1999). Additional work, on cellular responses in sea fans infected with fungal hyphae in the Florida Keys, showed that more granular amoebocytes were present adjacent to areas with fungal infections than were present elsewhere in the mesoglea (Mydlarz et al. 2008). Environmental parameters were also found to illicit responses in the granular amoebocytes of sea fans. Healthy sea fans, experimentally exposed to increasing water temperature over $8 \mathrm{~d}$ increased amoebocyte activity (Mydlarz et al. 2008). These data represent the first clear demonstration of a systemic reaction to elevated temperatures coordinated by the granular amoebocytes in corals, showing that coral immunity plays a role in sequestering both biotic and abiotic stressors (Mydlarz et al. 2008).

\section{ADAPTIVE IMMUNOLOGICAL RESPONSES}

\section{Self/non-self recognition and immunological memory}

B cells, a type of white blood cell that makes antibodies, or immunoglobulins in vertebrates' blood and other tissues (involving the humoral-immune response), and $\mathrm{T}$ cells (involving cell-mediated immune response) have not been found in invertebrates (Goldsby et al. 2003, Hauton \& Smith 2007). Yet, there is a form of cell recognition in corals. Hildemann et al. (1977) were the first to test for self/non-self recognition in a scleractinian coral, Montipora verrucosa. Grafting experiments were conducted to determine fusion or rejection potential. Intracolony isografts were consistently compatible and demonstrated soft-tissue fusion within 3 to $5 \mathrm{~d}$ after grafting. After a month, reconstitution was indistinguishable from normal ungrafted coral, and this compatible fusion persisted indefinitely. Conversely, the rejection of scleractinian allografts was preceded by a sensitization period of 2 to $3 \mathrm{wk}$ while intimate soft-tissue contact was established. Progressive blanching and loss of soft tissue occurred in the immediate contact area, yielding a 22 d median reaction time. Interestingly, when the same allograft pairs were reset, the median reaction time was reduced to $12 \mathrm{~d}$, implying immunological memory and specificity. The intensified reaction was marked by early hyperplasia and secretion of mucus at the tissue interfaces (Hildemann et al. 1977).

Similar results were later documented in a solitary reef coral, Fungia scutaria (Jokiel \& Bigger 1994). Further work on self versus non-self recognition of the coral Pocillopora damicornis showed that juvenile corals of different genotypes fused, while adult branches of the same species (but again of different genotypes) did not fuse (Hidaka 1985). These results suggest that juvenile corals lack the functional histocompatibility system shown by adults, at least in some species of hard corals. Self versus non-self recognition was not documented in a gorgonian soft coral until the 1990s (Salter-Cid \& Bigger 1991, Rinkevich 2004). Recently, Kvennefors et al. (2008) isolated a mannosebinding lectin that is thought to be involved in pathogen (and symbiont) recognition in the coral Acropora millepora. The lectin was shown to bind to nonself bacterial pathogens through recognition of mannose-like carbohydrates. Soft corals also display an adaptive 'memory' that speeds the recognition and inflammatory (immunological) response to a previous allograft, although the alloimmune memory fades after several months (Salter-Cid \& Bigger 1991).

Further evidence of an adaptive-like immunological response by a scleractinian coral comes from the eastern Mediterranean. For 8 yr, researchers isolated Vibrio shiloi bacteria from Oculina patagonica and infected the coral with the bacteria in aquaria experiments (Rosenberg et al. 2007). Since 2003, laboratory experiments have shown that $O$. patagonica had developed the ability to lyse the intracellular $V$. shiloi and avoid infection (Rosenberg et al. 2007). 


\section{Coral microbial diversity}

Genomic environmental probes combined with traditional culturing methods are rapidly increasing our appreciation of oceanic and coral-reef microbial diversity (Reed et al. 1999, Rohwer et al. 2001, 2002, Venter et al. 2004, Kellogg 2004, Rusch et al. 2007, Toledo-Hernandez et al. 2007a,b, Dinsdale et al. 2008, Kirchman 2008, Zuluaga-Montero 2009). Viruses, Archaea and other prokaryotes and microscopic eukaryotes need consideration and quantification when studying the host-immune responses to potential pathogens.

Many bacterial-community ribotypes (over 1000 bacterial 16S rDNAs) and high prokaryotic diversity (over 430 bacterial species by conservative analysis) have been documented from 3 corals of the Caribbean, Montastraea franksi, Diploria strigosa and Porites astreoides (Rohwer et al. 2002). None of the bacterialcommunity ribotypes from the 3 Caribbean corals belonged to the ubiquitous marine groups. Clearly, species-specific relationships are apparent among microbes. The most common identifiable group of coral-associated bacterial ribotypes was most closely related to known nitrogen fixers and antibiotic producers. The coral-holobiont model suggests that studies need to consider the full suite of associated prokaryotes that interact with the coral holobiont (Rohwer et al. 2002). It is possible that specialized microbiota occupying entry sites on the host, or that produce secondary antibiotics (metabolites), may protect the coral animal from pathogens (Rohwer et al. 2002). This concept has been used to manipulate reef corals' resistance to infectious disease through phage (viral) therapy (Efrony et al. 2007).

\section{Compromised-host hypothesis}

While prokaryotic microbes may infect a coral host for years without any apparent harm, cell signaling from a stressed host may allow a rapid change from subclinical infection to severe infection and host death. The human analogy is tuberculosis ( $\mathrm{MYCO}$ bacterium tuberculosis), a disease estimated to have asymptomatically infected one-third of the human population (Koul et al. 2004). Clearer insights into an anthozoan coral's immune response may provide the distinction between whether its associated microbes are in fact normal flora parasites, commensals, symbionts, or etiological agents of disease.
Differentiating the immune response of the host coral from pathogenic influences will provide insight into the opportunistic nature of potential pathogens (Fig. 2). As in humans (Rabin 1999), coral holobionts may be more susceptible to disease when environmentally stressed (Mydlarz et al. 2006, 2009, Lesser et al. 2007, Muller et al. 2008), becoming compromised and less resistant to diseases. Reduced tolerance to pathogens under heat stress may be directly related to the down-regulation of mannose-binding lectin, which binds to pathogen surfaces, directly compromising the immune defense system (Rodriguez-Lanetty et al. 2009). The growing incidence and susceptibility to tropical-marine diseases has been also attributed to increases in water temperatures, which may increase the virulence of primary infectious bacteria (Toren et al. 1998, Harvell et al. 2002). Still, anomalously high water temperatures may simply immunocompromise coral hosts, making them more susceptible to tropical marine diseases, whether or not infectious pathogens mutate to more virulent or less virulent forms. Therefore, understanding disease resistance and the influence of the corals' innate and potentially adaptive immune responses under environmental stress is critical as we move toward warmer oceans.

\section{DISCUSSION}

While the early Hildemann grafting experiment (Hildemann et al. 1977) with the reef coral Montipora verrucosa demonstrated allograft rejection with memory, similar to mammalian transplants, the mechanism(s) remain unclear. T cells have been implicated in mammalian allograft rejection when nude mice without thymus glands or functional $\mathrm{T}$ cells were found incapable of allograft rejection (Goldsby et al. 2003). Since corals also have neither $\mathrm{T}$ cells nor thymus glands, it seems pertinent to ask: (1) How is allograft rejection possible? (2) How do scleractinian corals achieve an accelerated allograft rejection capacity

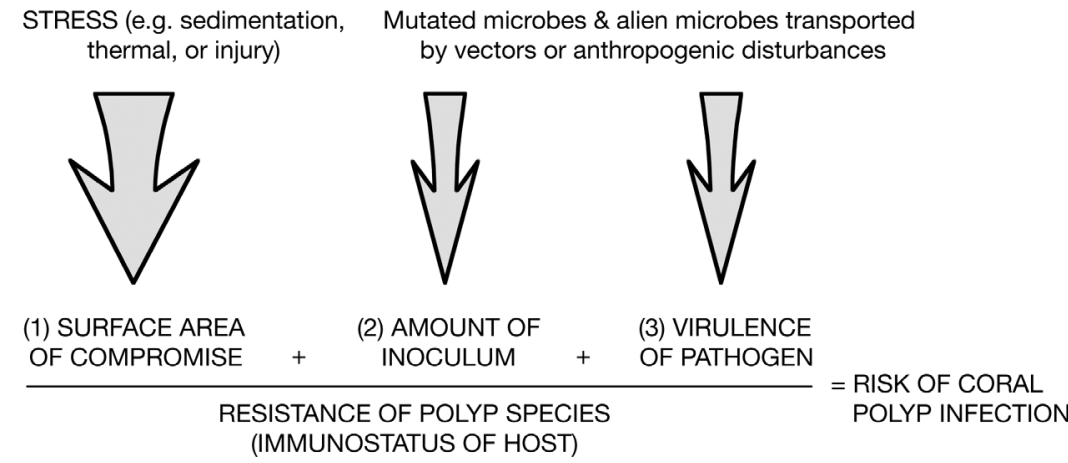

Fig. 2. Three primary factors influencing the risk of coral polyp infection within the context of the compromised-host hypothesis 
when allografts are reset? Could the coral model, which is basically a large gastrodermal cavity, provide an evolutionary remnant of the vertebrate immune response 'tool box'?

Corals do not have B cells. Mammalian T cells are associated with the cell-mediated immune response, whereas vertebrate B cells are associated with the humoral system. Researchers working with mice and human models may associate B cells with bone marrow origination and development. However, these cells mature in birds in the bursa of Fabricius (gut tissue) and in sheep and cattle in the fetal spleen. The rabbit's appendix and ileal Peyer's patch in the intestines of adult sheep and cattle are further examples of gutassociated tissues that supply B cells (Goldsby et al. 2003). Therefore, even (vertebrate) mammals do not use the same tissues for the proliferation and diversification of B cells. Still, the gastrodermal cells of coral may be a reasonable anatomical area on which to focus immunological research.

When one considers the evolutionary development of ancestral phagocytic cells in animal models as precursors to mammalian B cells and macrophages, researchers have shown that B cells (lymphocytes) in teleosts (trout fish) have potent in vivo and in vitro phagocytic activity. Human B cells have lost that innate ability. Data from the amphibian Xenopus laevis strongly suggested that the phagocytic capacity of B cells was not a trait uniquely acquired by teleost fishes but instead was already present in a common amphibian (Li et al. 2006). Coral and anemone amoebocytes also ingest and kill microbes, but may often digest their own symbionts as part of their normal diet (Boschma 1925, Titlyanov et al. 1996, Hutton \& Smith 1996, Downs et al. 2009), particularly under stress (Titlyanov et al. 1996). Notably, if we consider 5 phases of endocytosis and symbiont establishment, (1) contact, (2) engulfment, (3) recognition, (4) intracellular migration, and (5) repopulation, then only a slight variation in the recognition phase may change generic, nonselective, digestion to a system where the symbiont becomes established. Recognition, it turns out, can change throughout a coral's life-cycle and become more refined and selective as corals age (Little et al. 2004). However under stress, phagocytosis of symbionts seems to increase in corals (Titlyanov et al. 1996), which we suggest may be either because of reduced (symbiont) recognition or an upregulation of the immune response.

While the genetics of allorecognition and homologs to the vertebrate major histocompatibility complex (MHC) have been recently studied in a hydrozoan often found on hermit crab shells, these studies have yet to occur in reef corals (Mokady \& Buss 1996, Cadavid et al. 2004, Rinkevich 2004, Dishaw \& Litman
2009). As the genes for allogeneic immunorecognition become better defined in scleractinian corals, there will be opportunities to address (1) the maintenance of genetic variation, (2) the role of chimerism in distribution and abundance of reef building corals, and (3) the degree of conservation among allorecognition systems in reef-building coral taxa (Amar et al. 2008, Nicotra et al. 2009).

Recent reports show that the Anthozoa coral genome is more complex than other classes of Cnidaria, and more similar to humans than other 'higher' metazoans. Evidence of adaptive-like immunological mechanisms may result in a paradigm shift away from the perspective that anthozoans possess only innate immunological responses, and move toward the view that corals may also support other 'higher' immunological responses. Kortschak et al. (2003, p. 2193-2194) even stated that '...the expressed sequences of planula stage Acropora millepora appears to turn upside down several preconceived ideas about the evolution of animal genomes', highlighting the need to continue investigations on coral immunology. The increasing prevalence and incidence of marine diseases makes research all the more imperative on (1) the coral holobiont's immunological responses, (2) adaptive-like immunological mechanisms, and (3) the role of the pathogen versus the host. Such information may potentially lead to the prevention, or at least mitigation, of future coral disease outbreaks.

Acknowledgements. We thank S. van Woesik for editorial comments. We also thank the Coral Reef Targeted Research (CRTR) Program for supporting R.v.W. The CRTR Program is a partnership between the Global Environment Facility, the World Bank, The University of Queensland (Australia), and the United States National Oceanic and Atmospheric Administration (NOAA). Support for E.M.M. was provided by the NOAA Dr. Nancy Foster Scholarship and a Graduate Teaching Fellowship from the National Science Foundation (Florida Tech InSTEP Program) under grant Nos. DGE 0440529 and 0638702. This is Contribution Number 5 from the Institute for Research on Global Climate Change at the Florida Institute of Technology.

\section{LITERATURE CITED}

Amar KO, Chadwick N, Rinkevich B (2008) Coral kin aggregations exhibit mixed allogeneic reactions and enhanced fitness during early ontogeny. BMC Evol Biol 8:126

Bosch TCG, Augustin R, Anton-Erxleben F, Fraune S and others (2009) Uncovering the evolutionary history of innate immunity: the simple metazoan Hydra uses epithelial cells for host defence. Dev Comp Immunol 33:559-569

Boschma H (1925) On the feeding reactions and digestion in the coral polyp Astrangia danae, with notes on its symbiosis with zooxanthellae. Biol Bull 49:407-439

> Brown BE, Bythell JC (2005) Perspectives on mucus secretion in reef corals. Mar Ecol Prog Ser 296:291-309

Cadavid LF, Powell AE, Nicotra ML, Moreno M, Buss LW 
(2004) An invertebrate histocompatibility complex. Genetics 167:357-365

Cerenius L, Soderhall K (2004) The prophenoloxidaseactivating system in invertebrates. Immunol Rev 198: 116-126

Couch CS, Mydlarz LD, Harvell CD, Douglas NL (2008) Variation in measures of immunocompetence of sea fan coral, Gorgonia ventalina, in the Florida Keys. Mar Biol 155: 281-292

Davies PS (1984) The role of zooxanthellae in the nutritional energy requirements of Pocillopora eydouxi. Coral Reefs 2:181-186

Dinsdale EA, Pantos O, Smriga S, Edwards RA and others (2008) Microbial ecology of four coral atolls in the Northern Line Islands. PLoS One 3:e1584

> Dishaw LJ, Litman GW (2009) Invertebrate allorecognition: the origins of histocompatibility. Curr Biol 19:R286-R288

> Downs CA, Kramarsky-Winter E, Martinez J, Kushmaro A, Woodley CM, Loya Y, Ostrander K (2009) Symbiophagy as a cellular mechanism for coral bleaching. Autophagy 5: 211-216

Efrony R, Loya Y, Bacharach E, Rosenberg E (2007) Phage therapy of coral disease. Coral Reefs 26:7-13

Goldsby RA, Kindt TJ, Osborne BA, Kuby J (2003) Immunology, 5th edn. W. H. Freeman, New York, NY

Gould SJ, Vrba ES (1982) Exaptation-a missing term in the science of form. Paleobiology 8:4-15

> Harvell CD, Mitchell CE, Ward JR, Altizer S, Dobson AP, Ostfeld RS, Samuel MD (2002) Climate warming and disease risks for terrestrial and marine biota. Science 296:2158-2162

Hauton C, Smith VJ (2007) Adaptive immunity in invertebrates: a straw house without a mechanistic foundation. Bioessays 29:1138-1146

Hidaka M (1985) Tissue compatibility between colonies and between newly settled larvae of Pocillopora damicornis. Coral Reefs 4:111-116

> Hildemann WH, Raison RL, Cheung G, Hull CJ, Akaka L, Okamoto J (1977) Immunological specificity and memory in a scleractinian coral. Nature 270:219-223

Hutton DMC, Smith VJ (1996) Antibacterial properties of isolated amoebocytes from the sea anemone Actinia equina. Biol Bull 191:441-451

Jokiel PL, Bigger CH (1994) Aspects of histocompatibility and regeneration in the solitary reef coral Fungia scutaria. Biol Bull 186:72-80

Kellogg CA (2004) Tropical Archaea: diversity associated with the surface microlayer of corals. Mar Ecol Prog Ser 273:81-88

Kirchman DL (ed) (2008) Microbial ecology of the oceans, 2nd edn. John Wiley \& Sons, Hoboken, NJ

Koh EGL (1997) Do scleractinian corals engage in chemical warfare against microbes? J Chem Ecol 23:379-398

Kortschak RD, Samuel G, Saint R, Miller DF (2003) EST analysis of the Cnidarian Acropora millepora reveals extensive gene loss and rapid sequence divergence in the model invertebrates. Curr Biol 13:2190-2195

Koul A, Herget T, Klebl B, Ullrich A (2004) Interplay between mycobacteria and host signalling pathways. Nat Rev Microbiol 2:189-202

Kvennefors ECE, Leggat W, Hoegh-Guldberg O, Degnan BM, Barnes AC (2008) An ancient and variable mannosebinding lectin from the coral Acropora millepora binds both pathogens and symbionts. Dev Comp Immunol 32: 1582-1592

Lesser MP, Bythell JC, Gates RD, Johnstone RW, HoeghGuldberg O (2007) Are infectious diseases really killing corals? Alternative interpretations of the experimental and ecological data. J Exp Mar Biol Ecol 346:36-44

Li J, Barreda DF, Zhang Y, Boshra H and others (2006) B lymphocytes from early vertebrates have potent phagocytic and microbicidal abilities. Nat Immunol 7:1116-1125

> Little AF, van Oppen MJH, Willis BL (2004) Flexibility in algal endosymbioses shapes growth in reef corals. Science 304: 1492-1494

Metchnikoff E (1886) Embryologische Studien an Medusen. Ein Beitrag zur Genealogie der Primitiv-organe. Holder, Vienna

Meszaros A, Bigger C (1999) Qualitative and quantitative study of wound healing processes in the coelenterate, Plexaurella fusifera: spatial, temporal, and environmental (light attenuation) influences. J Invertebr Pathol 73:321-331

Miller DJ, Hemmrich G, Ball EE, Hayward DC and others (2007) The innate immune repertoire in Cnidariaancestral complexity and stochastic gene loss. Genome Biol 8:R59.1-R59.13

Mokady O, Buss LW (1996) Transmission genetics of allorecognition in Hydractinia symbiolongicarpus (Cnidaria: Hydrozoa). Genetics 143:823-827

Muller EM, Rogers CR, Spitzack AS, van Woesik R (2008) Bleaching increases the likelihood of disease on Acropora palmata (Lamarck) in Hawksnest Bay, St. John, US Virgin Islands. Coral Reefs 27:191-195

Muscatine L, Falkowski P, Porter J, Dubinsky Z (1984) Fate of photosynthetically-fixed carbon in light and shadeadapted colonies of the symbiotic coral Stylophora pistillata. Proc R Soc Lond B Biol Sci 222:181-202

> Mydlarz LD, Jones LE, Harvell CD (2006) Innate immunity, environmental drivers, and disease ecology of marine and freshwater invertebrates. Annu Rev Ecol Evol Syst 37:251-288

Mydlarz LD, Holthouse SF, Peters EC, Harvell CD (2008) Cellular responses in sea fan corals: granular amoebocytes react to pathogen and climate stressors. PLoS One 3:e1811

> Mydlarz LD, Couch CS, Weil E, Smith G, Harvell CD (2009) Immune defenses of healthy, bleached and diseased Montastraea faveolata during a natural bleaching event. Dis Aquat Org 87:67-78

Nicotra ML, Powell AE, Rosengarten RD, Moreno $M$ and others (2009) A hypervariable invertebrate allodeterminant. Curr Biol 19:583-589

Olano CT, Bigger CH (2000) Phagocytic activities of the gorgonian coral Swiftia exserta. J Invertebr Pathol 76:176-184

> Palmer CV, Mydlarz LD, Willis BL (2008) Evidence of an inflammatory-like response in non-normally pigmented tissues of two scleractinian corals. Proc Biol Sci 275: 2687-2693

Petes LE, Harvell CD, Peters EC, Webb MAH, Mullen KM (2003) Pathogens compromise reproduction and induce melanization in Caribbean sea fans. Mar Ecol Prog Ser 264:167-171

Rabin BS (1999) Immune function and health: the connection. Wiley-Liss \& Sons, New York, NY

Ratcliffe NA (1991) The prophenoloxidase system and its role in arthropod immunity. In: Warr GW, Cohen N (eds) Phylogenesis of immune functions. CRC Press, Boca Raton, FL, p 45-72

Reed KC, Crowell MC, Castro MD, Sloan ML (1999) Skin and soft-tissue infections after injury in the ocean: culture methods and antibiotic therapy for marine bacteria. Mil Med 164:198-201

Rinkevich B (2004) Allorecognition and xenorecognition in reef corals: a decade of interactions. Hydrobiologia 530531:443-450

Ritchie KB (2006) Regulation of microbial populations by coral surface mucus and mucus-associated bacteria. Mar Ecol Prog Ser 322:1-14 
Rodriguez-Lanetty M, Saki H, Hoegh-Guldberg O (2009) Early molecular responses of coral larvae to hyperthermal stress. Mol Ecol 18:5101-5114

Rohwer F, Breithart M, Jara J, Azam F, Knowlton N (2001) Diversity of bacteria associated with the Caribbean coral Montastraea franksi. Coral Reefs 20:85-91

Rohwer F, Seguritan V, Azam F, Knowlton N (2002) Diversity and distribution of coral-associated bacteria. Mar Ecol Prog Ser 243:1-10

Rosenberg E, Koren O, Reshef L, Efrony R, Rosenberg IZ (2007) The role of microorganisms in coral health, disease and evolution. Nat Rev Microbiol 5:355-362

Rusch DB, Halpern AL, Sutton G, Heidelberg KB and others (2007) The Sorcerer II Global Ocean Sampling Expedition: northwest Atlantic through eastern tropical Pacific. PLoS Biol 5:e77

Salter-Cid L, Bigger CH (1991) Alloimmunity in the gorgonian coral Swiftia exserta. Biol Bull 181:127-134

Stoskopf MK (2006) Coelenterates. In: Lewbart GA (ed) Invertebrate medicine. Blackwell Publishing, Ames, IA, p 19-51

- Technau U, Rudd S, Maxwell P, Gordon PMK and others (2005) Maintenance of ancestral complexity and nonmetazoan genes in two basal cnidarians. Trends Genet

Editorial responsibility: John Austin, Oldendorf/Luhe, Germany
21:633-639

Titlyanov EA, Titlyanova TV, Letetkin VA, Tsukahara J, van Woesik R, Yamazato K (1996) Degradation of zooxanthellae and regulation of their density in hermatypic corals. Mar Ecol Prog Ser 139:167-178

Toledo-Hernandez C, Sabat AM, Zuluaga-Montero (2007a) Density, size structure and aspergillosis prevalence in Gorgonia ventalina at six localities in Puerto Rico. Mar Biol 152:527-535

Toledo-Hernandez C, Bones-Gonzalez A, Ortiz-Vazquez OE, Sabat AM, Bayman P (2007b) Fungi in the sea fan Gorgonia ventalina: diversity and sampling strategies. Coral Reefs 26:725-730

- Toren A, Landau L, Kushmaro A, Loya Y, Rosenberg E (1998) Effect of temperature on adhesion of Vibrio Strain AK-1 to Oculina patagonica and on coral bleaching. Appl Environ Microbiol 64:1379-1384

> Venter JC, Remington K, Heidelberg JF, Halpern AL and others (2004) Environmental genome shotgun sequencing of the Sargasso Sea. Science 304:66-74

Zuluaga-Montero A (2009) Aspergillosis in sea fans: phylogenetic relationship among aspergillosis strains and patterns of prevalence. Reef Encounter 37:12-13

Submitted: September 1, 2009; Accepted: February 3, 2010 Proofs received from author(s): May 17, 2010 